\title{
DESAIN INSTALASI PENGOLAHAN AIR LIMBAH (IPAL) BIOFILTER UNTUK MENGOLAH AIR LIMBAH POLIKLINIK UNIPA SURABAYA
}

\author{
Rhenny Ratnawati*) Muhammad Al Kholif*) dan Sugito*)
}

\begin{abstract}
Abstrak
Poliklinik menghasilkan air limbah domestik yang bersifat infeksius. Oleh karenanya air limbah tersebut harus diolah agar memenuhi baku mutu lingkungan sehingga tidak mengakibatkan terjadinya penyakit. Aplikasi biofilter untuk mengolah air limbah domestik poliklinik dapat mereduksi beban organik terlarut sehingga menghasilkan efluen yang layak dibuang ke badan air. Efluen yang dihasilkan dapat ditingkatkan sebagai air baku untuk air bersih. Tujuan dalam penelitian ini adalah merencanakan Instalasi Pengolahan Air Limbah (IPAL) untuk mengolah air limbah poliklinik UNIPA Surabaya dengan menggunakan biofilter. Teknologi biofilter dipilih karena keunggulannya dalam meremoval pencemar organik dengan tingkat efisiensi tinggi sampai dengan 95\%. Biofilter tidak membutuhkan lahan yang luas serta menggunakan media yang sangat murah menjadikan kelebihan tersendiri dari teknologi ini. Metode penelitian ini menggunakan data dokumentasi dan observasi lapangan bangunan gedung poliklinik UNIPA Surabaya. Data kebutuhan air bersih diprediksikan berdasarkan kebutuhan air yang digunakan untuk operasional poliklinik. Hasil penelitian ini berupa desain IPAL Biofilter yang meliputi dimensi bangunan dan gambar teknik IPAL serta perhitungan biaya yang siap diaplikasikan untuk mengolah air limbah yang dihasilkan oleh poliklinik UNIPA Surabaya.
\end{abstract}

Kata kunci: air limbah poliklinik, biofilter, IPAL

\section{PENDAHULUAN}

Rumah sakit atau poliklinik merupakan fasilitas sosial yang keberadaannya sangat penting bagi masyarakat. Air limbah yang berasal dari limbah poliklinik merupakan salah satu sumber pencemaran air yang sangat potensial. Hal ini disebabkan karena air limbah poliklinik mengandung senyawa organik yang cukup tinggi juga kemungkinan mengandung senyawa-senyawa kimia lain serta mikroorganisme patogen yang dapat menyebabkan penyakit terhadap masyarakat di sekitarnya. Oleh karena potensi dampak air limbah poliklinik terhadap kesehatan masyarakat sangat besar, maka setiap poliklinik diharuskan mengolah air limbahnya sampai memenuhi persyaratan standar yang berlaku (Ahmadi dan Fahmi Umar, 1995) .

Poliklinik Universitas PGRI Adi Buana (UNIPA) Surabaya sebagai salah satu unit pelaksanaan di UNIPA Surabaya dibangun untuk memberikan pelayanan kesehatan dasar setrata pertama kepada masyarakat secara langsung di wilayah kampus Dukuh Menanggal Surabaya dan sekitarnya. Poliklinik UNIPA Surabaya dibangun sebagai sarana laboratorium kebidanan bagi mahasiswa serta pengembangan enterpreneur lulusan. Berbagai kegiatan poliklinik yang meliputi aktivitas domestik (kerumah tanggaan) maupun aktivitas pelayanan kesehatan pada masyarakat dapat menjadi sumber pencemar limbah cair, padat dan gas yang berbahaya bila tidak ditangani secara benar. Sumber limbah cair poliklinik dapat berasal dari kamar mandi, dapur, ruang periksa, laboratorium, ruang operasi dan ruangan lain yang mengandung bahan berbahaya serta kuman penyakit. Adapun karakteristik air limbah poliklinik dengan rawat inap atau rawat jalan hampir secara keseluruhan memiliki kesamaan dengan air limbah rumah sakit, yang meliputi: limbah domestik yakni buangan kamar mandi, dapur, air bekas cucian pakaian; limbah cair klinis yakni limbah dari kegiatan klinis misalnya air bekas cuci luka, cucian darah dan lain - lain; air limbah laboratorium; dan lainnya. Kapasitas air limbah poliklinik relatif kecil sehingga perlu di kembangkan teknologi pengolahan air limbah yang murah, mudah operasinya serta harganya terjangkau.

Kep-MENLH/12/1995 tentang baku mutu limbah cair bagi kegiatan Rumah Sakit mengharuskan setiap rumah sakit harus mengolah air limbah sampai standart yang diijinkan.

\footnotetext{
*) Dosen Teknik Lingkungan Universitas PGRI Adi Buana Surabaya
} 
Menurut Kepgub Jatim 61/ 1999 tentang baku mutu limbah cair bagi kegiatan Rumah Sakit di Propinsi Daerah Tingkat I Jatim, menyebutkan bahwa dalam rangka penanganan masalah limbah cair, harus memenuhi ketentuan-ketentuan antara lain:(1) membuat saluran pembuangan limbah cair tertutup dan kedap air, sehingga tidak terjadi perembesan ke tanah dan di alirkan ke IPAL serta terpisah dengan saluran limpahan air hujan, (2) melakukan pengolahan limbah cair secara fisika, kimia dan biologi, sehingga mutu limbah cair yang di buang ke lingkungan tidak melampaui Baku Mutu Limbah Cair bagi Rumah Sakit yang telah ditetapkan. Bagi rumah sakit besar umumnya dapat membangun IPAL sendiri karena mempunyai dana yang cukup, tetapi bagi rumah sakit kecil termasuk poliklinik dan puskesmas maka kebutuhan akan teknologi pengolahan air limbah yang layak secara teknis,ekonomis dan memenuhi standart lingkungan sangat diperlukan.

Teknologi pengolahan air limbah sederhana dengan kinerja yang tinggi yang telah dikembangkan saat ini adalah dengan biofilter. Menurut Metcalf \& Eddy (2004) biofilter (Submerged Filter) adalah suatu istilah dari reaktor yang dikembangkan dengan prinsip mikroba tumbuh dan berkembang pada suatu media filter dan membentuk lapisan biofilm (attached growth). Biofilm merupakan salah satu pengolahan limbah cair secara biologis, proses kerjanya memanfaatkan kehidupan mikroorganisme untuk menguraikan polutan. Adapun beberapa keunggulan antara lain pengoperasiannya mudah, lumpur yang dihasilkan sedikit, tahan terhadap fluktuasi jumlah air limbah maupun fluktuasi konsentrasi serta dapat menghilangkan padatan tersuspensi dengan baik. Teknologi biofilter mampu meremoval kandungan bahan organik sampai tingkat efisiensi $95 \%$.

Tujuan yang ingin dicapai pada penelitian ini adalah merencanakan IPAL biofilter anaerob-aerob yang meliputi ukuran dimensi utama bangunan berdasarkan prediksi peningkatan kunjungan dan pengembangan poliklinik untuk 10 tahun mendatang.

\section{METODA PENELITIAN}

\section{Lokasi Penelitian}

Lokasi penelitian perencanaan IPAL Biofilter adalah di Poliklinik UNIPA Surabaya yang terletak di kampus II Jl.Dukuh Menanggal XII/4 Surabaya.

\section{Inventarisasi Data}

Penelitian ini menggunakan data sekunder dan data primer. Data sekunder yang dikumpulkan antara lain:

- Profil poliklinik

- Layout poliklinik

- Fasilitas pelayanan

Sedangkan kegiatan pengumpulan data primer mencakup sebagai berikut:

- Lokasi pembuangan air limbah

- Kualitas air limbah (fisik dan kimia dan biologi)

- Debit air limbah

\section{Perencanaan Desain IPAL}

\section{a. Perhitungan Debit Air Limbah}

Menurut Butter \& Davies dalam Sugito (2005) bahwa terdapat hubungan yang sangat erat antara jumlah pemakaian air rata - rata perorang per hari terhadap air limbah yang dihasilkan dan dapat dirumuskan secara sederhana sebagai berikut :

$$
\mathrm{Q} 1=\mathrm{x} . \mathrm{Q}
$$

Dimana : $Q$ adalah konsumsi air bersih per orang per hari

Q1 adalah timbulan air limbah per orang per hari

$$
\mathrm{x} \text { adalah faktor pengembalian }
$$

Dalam perencanaan pembangunan IPAL ini, peneliti menggunakan perhitungan jumlah timbulan air limbah rata - rata per hari adalah $90 \%$ dari pemakaian air bersih rata rata per hari.

\section{b. Desain IPAL Biofilter}

Desain bangunan utama IPAL biofilter yang direncanakan adalah sebagai berikut :

a. Bak equalisasi/ Bak pengumpul terbuat dari pasangan batu bata, bentuk persegi panjang dilengkapi dengan Bar Screen berupa kawat yang terbuat dari stainlies.

b. Bak Sedimentasi/ Bak pengendapan awal terbuat dari pasangan batu bata dan tertutup yang dilengkapi dengan lubang kontrol, bak berbentuk persegi panjang, air limbah masuk melalui pipa inlet secara gravitasi, pemeliharaan dengan cara pengurasan manual.

Kriteria perencanaan menurut standart JWWA dalam Said (2006) adalah:

- Waktu tinggal (Retention time) rata - rata $=3-5$ jam

- Beban permukaan (surface loading) $=20-50 \mathrm{~m}^{3} / \mathrm{m}^{2} /$ hari. 
c. Reaktor Biofilter Anaerob, reaktor ini dipasang secara seri terhadap reaktor biofilter aerob, dengan bahan pasangan batu bata berbentuk persegi panjang tertutup, media filter yang digunakan batu apung dan kerikil/pecahan batu kali dengan diameter 2-3 cm, fluida/ air limbah dialirkan secara down flow dan upflow.

Kriteria perencanaan menurut standar JWWA dalam Said(2006) adalah :

- Waktu tinggal total rata - rata

$$
\text { = 6-8 jam }
$$

- $\quad$ Tinggi ruang lumpur

$$
=0,4 \mathrm{~m}
$$

- Tinggi media pembiakan mikroba $=0,9-1,5 \mathrm{~m}$

- Tinggi air di atas bed media $=0,2 \mathrm{~m}$

- Beban BOD per volume media $=0,4-4,7 \mathrm{~kg} \mathrm{BOD} / \mathrm{m}^{3} /$ hari

- Beban BOD per satuan permukaan media $($ La $)=5-30 \mathrm{~g} \mathrm{BOD} / \mathrm{m}^{2} /$ hari.

d. Kebutuhan oksigen :

Kebutuhan oksigen di dalam reaktor biofilter aerob sebanding dengan jumlah BOD yang dihilangkan. Aerasi dilakukan dengan menghembuskan udara dari blower melalui Perforated Pipe diffuser yang dipasang di dalam air dengan buka - tutup secara otomatis. Jika suplai udara dihentikan maka diffuser akan tertutup secara otomatis (Siregar, 2005).

e. Bak Pengendap Akhir

Bak pengendap akhir terbuat dari pasangan bata dan tertutup dilengkapi lubang kontrol, bentuk bak persegi panjang dengan pipa inlet dan outlet secara gravitasi. Bak ini berfungsi sebagai pengendap akhir sesuai kebutuhan dan air limpasan masuk ke bak khlorinator.

Kriteria perencanaan menurut standar JWWA dalam Said, (2006) adalah :

- Waktu tinggal ( Retention time ) rata - rata $=2-5$ jam

- Beban Permukaan (Surface Loading) $=20-50 \mathrm{~m}^{3} / \mathrm{m}^{2} /$ hari

f. Klorinator (Bak pembubuh Kaporit) Klorinasi direncanakan dengan alat dosing pump/infuse chlorinator, dimana larutan klorin pada konsentrasi yang terukur dialirkan ke dalam air limpasan IPAL melalui saluran selang yang dilengkapi pengatur aliran/kran (Said, 2006).

\section{Analisis Data}

Metode analisis data dilakukan secara diskriptif kuantitatif dilakukan dengan cara :

a. Perhitungan perencanaan dimensi bangunan utama pengolahan air limbah berdasarkan kriteria perencanaan dan debit air limbah yang direncanakan.

b. Desain perencanaan berupa gambar teknik IPAL Biofilter.

c. Perhitungan biaya pembangun IPAL biofilter disesuaikan dana yang ada dengan menggunakan perhitungan analisis biaya konstruksi/bangunan (Zainal. Z. 2005) dan pedoman standart harga barang/jasa Kota Surabaya tahun 2014.

\section{HASIL DAN PEMBAHASAN}

\section{Penggunaan Lahan dan Fasilitas}

Luas lahan yang disiapkan untuk pembangunan Poliklinik UNIPA Surabaya Jalan Dukuh Menanggal XII adalah $324 \mathrm{~m}^{2}$ yang terdiri dari 3 lantai dengan rencana kapasitas pelayanan pasien adalah sebanyak 10 (sepuluh) tempat tidur.

\section{Perhitungan Bangunan IPAL Poliklinik UNIPA Surabaya}

Penelitian ini dilakukan untuk merencanakan IPAL Poliklinik UNIPA Surabaya dengan asumsi untuk 10 tahun ke depan dengan menggunakan sistem pengolahan kombinasi biofilter anaerobaerob. Karakteristik beban pencemar BOD yang digunakan berdasarkan pada karakteristik limbah cair Rumah Sakit dengan beban pencemar yaitu $300 \mathrm{mg} / \mathrm{l}$. Debit influent yang digunakan yaitu sebesar $20 \mathrm{~m}^{3} /$ hari yang diperoleh berdasarkan perhitungan kebutuhan air bersih selama pengoperasian Poliklinik. Efisiensi pengolahan yang direncanakan yaitu berkisar antara 90 - $95 \%$ sesuai dengan efisiensi pengolahan dengan sistem kombiasi anaerob - aerob.

Untuk mengetahui perencanaan IPAL yang diinginkan, maka terlebih dahulu harus diketahui sumber - sumber limbah yang dihasilkan dari proses pengoperasian Klinik UNIPA Surabaya. Berikut diagram proses pengolahan limbah cair Polikinik UNIPA Surabaya seperti yang terlihat pada Gambar 3.1 


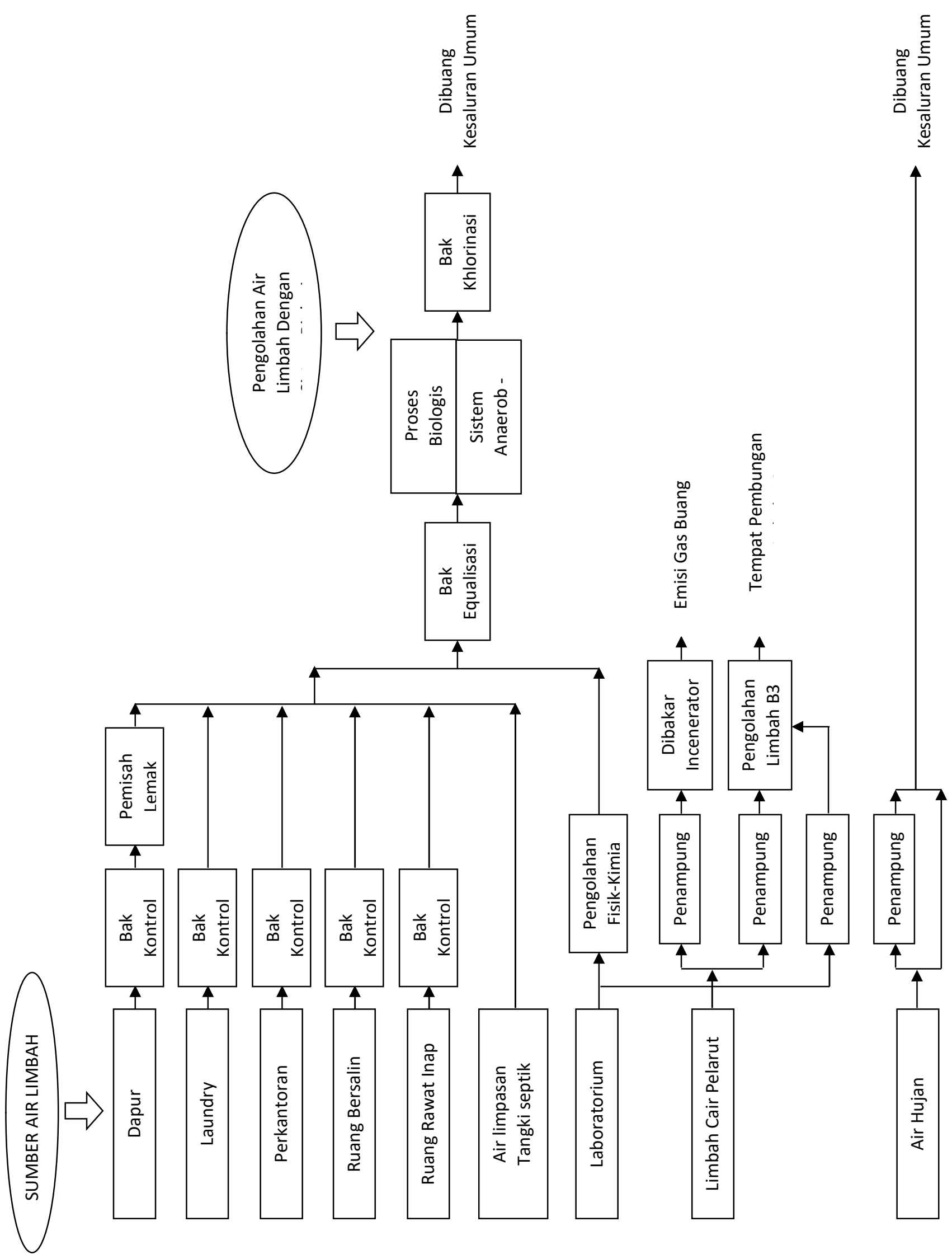

Gambar 3.1. Diagram Proses Pengolahan Limbah Poliklinik UNIPA Surabaya 
3. Desain Teknis IPAL Poliklinik UNIPA Surabaya.

Kapasitas IPAL Domestik yang direncanakan pada Poliklinik UNIPA Surabaya alaha sebagai berikut:

- Kapasitas Pengolahan: $20 \mathrm{~m}^{3} / \mathrm{hari}=$ $0,83 \mathrm{~m}^{3} / \mathrm{jam}=13,83 \mathrm{liter} / \mathrm{menit}$

- BOD air limbah rata-rata : $300 \mathrm{mg} / \mathrm{liter}$

- Konsentrasi SS : $300 \mathrm{mg} / \mathrm{liter}$

- Total efisiensi pengolahan: $90-95 \%$

- BOD air olahan : : $20 \mathrm{mg} / \mathrm{l}$

- SS air olahan : :20 mg/l

4. Perhitungan Desain

A. Desain Bak Pemisah Lemak/Minyak

Bak pemisah lemak/minyak (grease removal) yang direncanakan adalah dengan aliran gravitasi sederhana. Bak ini dilengkapai dengan bar screen pada bagian inletnya.

Kapasitas Pengolahan:20 $\mathrm{m}^{3} /$ hari $=$ $0,83 \mathrm{~m}^{3} / \mathrm{jam}=13,83 \mathrm{liter} / \mathrm{menit}$

Kriteria perencanaan: Retention time $=$ \pm 60 menit

Volume bak yang diperlukan

$=\frac{60}{60 \times 24}$ hari $\times 20 \mathrm{~m}^{3} /$ hari

$=0,8 \mathrm{~m}^{3} \approx 1 \mathrm{~m}^{3}$

Dimensi Bak direncanakan :

Panjan : $1,0 \mathrm{~m}$

Lebar : $1,0 \mathrm{~m}$

Tinggi : $1,0 \mathrm{~m}$

Ruang bebas (Free board) :0,2 m

Volume efektif : $1,0 \mathrm{~m}^{3}$

Tebal dinding : $15 \mathrm{~cm}$

Desain bak pemisah lemak/minyak ditunjukan pada Gambar 3.2.

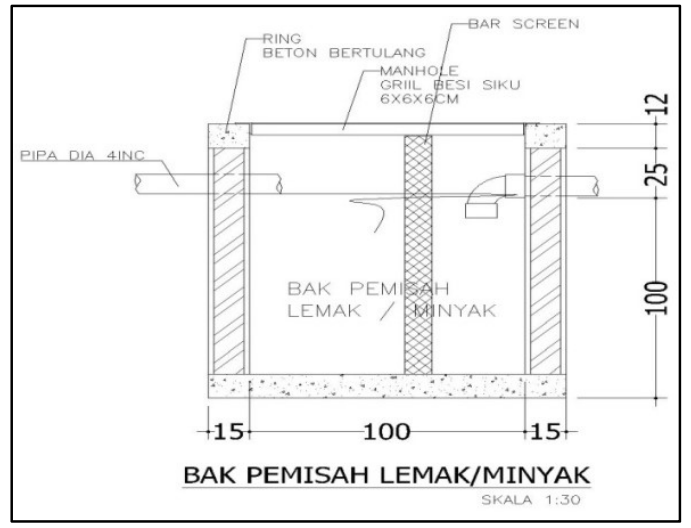

Gambar 3.2. Bak Pemisah lemak/Minyak

\section{B. Desain Bak Equalisasi/Bak Sumur Pengumpul \\ Waktu tinggal di dalam bak $(\mathrm{HRT})=2$ - 8 jam (JWWA dalam Said, 2006)}

Ditetapkan : waktu tinggal (td) limbah di dalam bak equalisasi $=2 \mathrm{jam}$

$$
\begin{aligned}
& \text { Volume bak yang diperlukan } \\
& =\frac{2}{24} \text { hari } \times 20 \mathrm{~m}^{3} / \text { hari }=1,6 \mathrm{~m}^{3}
\end{aligned}
$$

Dimensi Bak direncanakan :

$$
\begin{array}{ll}
\text { Panjang } & : 1,4 \mathrm{~m} \\
\text { Lebar } & : 1,2 \mathrm{~m} \\
\text { Tinggi } & : 1,0 \mathrm{~m} \\
\text { Ruang bebas (Free board) } & : 0,2 \mathrm{~m} \\
\text { Volume efektif } & : 1,6 \mathrm{~m}^{3} \\
\text { Tebal dinding } & : 15 \mathrm{~cm} \\
\text { Chek } & \multicolumn{2}{c}{\text { td (jam) }=\frac{\text { Volume efektif }\left(\mathrm{m}^{3}\right)}{\text { debit }\left(\mathrm{m}^{3} / \text { hari }\right)}} \\
\mathrm{td}=\frac{1,6 \mathrm{~m}^{3}}{20 \mathrm{~m}^{3} / \text { hari }}=0,08 \text { hari x } 24 \mathrm{jam} \\
\quad=1,92 \text { jam } \approx 2 \mathrm{Jam}
\end{array}
$$

jadi, waktu tinggal (td) di dalam bak $=\mathbf{2}$ jam, sesuai dengan kriteria.

Pompa Air Limbah $=20 \mathrm{~m}^{3} /$ hari $=0,83$ $\mathrm{m}^{3} / \mathrm{jam}=13,83$ liter $/$ menit

Desain bak equalisasi ditunjukan pada Gambar 3.3.

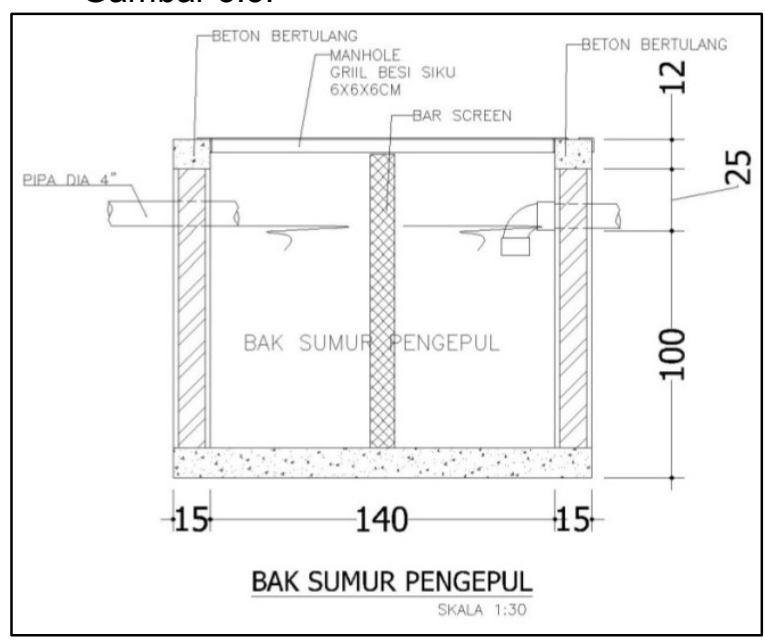

Gambar 3.3 Bak Equalisasi/Sumur

Pengumpul

\section{Desain Bak Pengendapan Awal/Bak Sedimentasi Awal}

Debit Air Limbah : $20 \mathrm{~m}^{3} /$ hari

$$
\begin{aligned}
& : 0,83 \mathrm{~m}^{3} / \mathrm{jam} \\
& : 13,83 \text { liter/menit }
\end{aligned}
$$

BOD masuk $\quad: 300 \mathrm{mg} / \mathrm{liter}$

Efisiensi $: 20 \%$

BOD keluar $: 240 \mathrm{mg} / \mathrm{liter}$

Waktu tinggal di dalam bak (HRT) $=2-4$ jam (JWWA dalam Said, 2006)

Ditetapkan : waktu tinggal (td) limbah di dalam bak equalisasi $=2 \mathrm{jam}$ Jadi, 
Volume bak yang diperlukan $=\frac{2}{24} \times 20 \mathrm{~m}^{3}$

$$
=1,6 \mathrm{~m}^{3}
$$

Dimensi Bak direncanakan :

Panjang : 1,4 m

Lebar : :1,2 m

Tinggi : :1,0 m

Ruang bebas (Free board) $: 0,2 \mathrm{~m}$

Volume efektif : 1,6 $\mathrm{m}^{3}$

Tebal dinding $: 15 \mathrm{~cm}$

\section{Chek:}

$\operatorname{td}($ jam $)=\frac{\text { Volume efektif }\left(m^{3}\right)}{\text { debit }\left(m^{3} / \text { hari }\right)}$

$\mathrm{td}=\frac{1,6 \mathrm{~m}^{3}}{20 \mathrm{~m}^{3} / \text { hari }}=0,08$ hari $\mathrm{x} 24 \mathrm{jam}$

$$
=1,92 \mathrm{jam} \approx 2 \mathrm{Jam}
$$

jadi, waktu tinggal (td) di dalam bak $=\mathbf{2}$ jam sesuai dengan kriteria.

Beban permukaan (surface loading)

$$
\begin{aligned}
& =\frac{\text { Debit }(\mathrm{Q})}{\text { Panjang } \mathrm{L} \text { Lebar }} \\
& =\frac{20 \mathrm{~m}^{3} / \text { hari }}{1,6 \mathrm{~m} \mathrm{x} 1,0 \mathrm{~m}} \\
& =12,5 \mathrm{~m}^{3} / \mathrm{m}^{2} . \text { hari }
\end{aligned}
$$

> Waktu tinggal pada saat beban puncak $=1$ jam (asumsi jumlah limbah $2 \times$ jumlah rata-rata)

$>$ Beban permukaan (surface loading) rata-rata $=12,5 \mathrm{~m}^{3} / \mathrm{m}^{2}$. hari

> Beban permukaan pada saat puncak $=25 \mathrm{~m}^{3} / \mathrm{m}^{2}$. hari

$>$ Beban permukaan $=20-50$ $\mathrm{m}^{3} / \mathrm{m}^{2}$.hari

Desain bak pengendapan awal/ sedimentasi ditunjukan pada gambar 3.4 berikut.

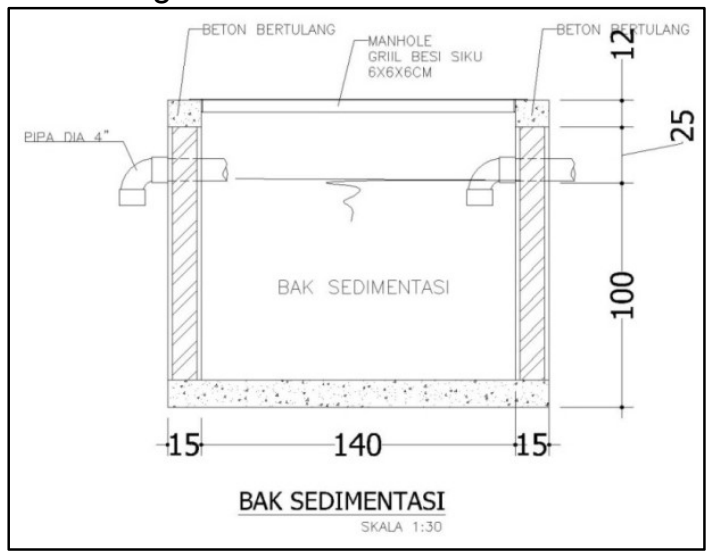

Gambar 3.4. Bak Pengendapan Awal/ Sedimentasi Awal

\section{Bak Biofilter Anaerob}

Debit air limbah:20 $\mathrm{m}^{3} / \mathrm{hari}$

BOD masuk : $240 \mathrm{mg} / \mathrm{liter}$

Efisiensi $: 70 \%$

BOD keluar : $72 \mathrm{mg} / \mathrm{liter}$
Untuk pengolahan air dengan proses biofilter standar beban BOD per volume media 0,4 $4,7 \mathrm{Kg} \mathrm{BOD} / \mathrm{m}^{3}$.hari, (Nusa Idaman Said, BPPT, 2006).

Ditetapkan beban BOD yang digunakan $=4$ $\mathrm{Kg} \mathrm{BOD} / \mathrm{m}^{3}$.hari.

Beban BOD di dalam air limbah $=20 \mathrm{~m}^{3} /$ hari $x 240 \mathrm{~g} / \mathrm{m}^{3}=4.800 \mathrm{~g} / \mathrm{hari}=4,8 \mathrm{~kg} / \mathrm{hari}$

Volume media yang diperlukan

$$
=\frac{4,8 \mathrm{~kg} / \mathrm{hari}}{4 \mathrm{~kg} / \mathrm{m}^{3} \cdot \text { hari }}=1,2 \mathrm{~m}^{3}
$$

Volume media $=75 \%$ dari total volume reaktor

Volume reaktor yang diperlukan

$$
=\frac{100}{75} \times 1,2 \mathrm{~m}^{3}=1,6 \mathrm{~m}^{3}
$$

Waktu tinggal di dalam reaktor anaerob

$$
\begin{gathered}
=\frac{1,6 \mathrm{~m}^{3}}{20 \mathrm{~m}^{3} / \text { hari }} \times 24 \mathrm{jam} / \text { hari }=1,92 \mathrm{jam} \\
\approx 2 \mathrm{jam}
\end{gathered}
$$

Dimensi Bak direncanakan :

Panjang: $1,4 \mathrm{~m}$

Lebar: $1,2 \mathrm{~m}$

Tinggi: $1,0 \mathrm{~m}$

Ruang bebas (Free board):0,2 m

Volume efektif: $1,6 \mathrm{~m}^{3}$

Tebal dinding: $15 \mathrm{~cm}$

\section{Chek:}

$$
\begin{aligned}
& \operatorname{td}(\text { jam })=\frac{\text { Volume efektif }\left(\mathrm{m}^{3}\right)}{\text { debit }\left(\mathrm{m}^{3} / \text { hari }\right)} \\
& \begin{array}{c}
\operatorname{td}=\frac{1,6 \mathrm{~m}^{3}}{20 \mathrm{~m}^{3} / \text { hari }} \times 24 \mathrm{jam} / \text { hari }=1,92 \mathrm{jam} \\
\approx 2 \mathrm{jam}
\end{array}
\end{aligned}
$$

jadi, waktu tinggal (td) di dalam bak $=\mathbf{2}$ jam sesuai dengan kriteria

$>$ Waktu tinggal rata-rata $: 2$ jam

$>$ Tinggi ruang lumpur:0,1 m

$>$ Tinggi bed media pembiakan mikroba: $1,0 \mathrm{~m}$

$>\quad$ Tinngi air di atas bed media:0,2 $\mathrm{m}$

$>$ Volume media pada biofilter anaerob:1,4 m x 1,2 m x 1,0 m = 1,6 $\mathrm{m}^{3}$ Beban BOD per volume media

$$
\begin{aligned}
& =\frac{4,8 \mathrm{Kg} \mathrm{BOD} / \text { hari }}{1,6 \times 1,0 \times 1} \\
& =3 \mathrm{Kg} \mathrm{BOD} / \mathrm{m}^{3} \text { hari }
\end{aligned}
$$

Standar high rate tricling filter : 0,4-4,7

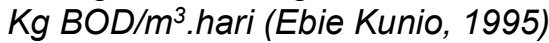

\section{E. Bak Biofilter Aerob}

Debit air limbah:20 $\mathrm{m}^{3} / \mathrm{hari}$

BOD masuk:72 mg/liter

Efisiensi:60 \%

BOD keluar:26 mg/liter

Beban BOD di dalam air limbah $=20$ $\mathrm{m}^{3} /$ hari $\times 72 \mathrm{~g} / \mathrm{m}^{3}=1.440 \mathrm{~g} /$ hari $=1,44$ $\mathrm{kg} / \mathrm{hari}$ 
Jumlah BOD yang dihilangkan

$$
\begin{aligned}
& =\frac{60}{100} \times 1,44 \mathrm{Kg} / \mathrm{hari} \\
& =0,864 \mathrm{Kg} / \mathrm{hari}
\end{aligned}
$$

Beban BOD per volume media yang digunakan $=1 \mathrm{Kg} / \mathrm{m}^{3}$.hari

Volume media yang diperlukan

$$
\begin{aligned}
& =\frac{0,864 \mathrm{~kg} / \text { hari }}{1 \mathrm{~kg} / \mathrm{m}^{3} \text {. hari }} \\
& =0,864 \mathrm{~m}^{3}
\end{aligned}
$$

Volume media $=50 \%$ dari total volume reaktor

Volume reaktor yang diperlukan

$$
\begin{aligned}
& =\frac{100}{50} \times 0,864 \mathrm{~m}^{3} \\
& =1,7 \mathrm{~m}^{3}
\end{aligned}
$$

Waktu tinggal di dalam reaktor anaerob

$$
\begin{array}{r}
=\frac{1,7 \mathrm{~m}^{3}}{20 \mathrm{~m}^{3} / \text { hari }} \times 24 \mathrm{jam} / \text { hari } \\
=2,04 \mathrm{jam}
\end{array}
$$

Biofilter aerob terdiri dari dua rungan yaitu ruang aerasi dan ruang bed media Dimensi Reaktor Biofilter Aerob direncanakan terdiri dari : (seperti gambar 3.5)

\section{Ruang Aerasi :}

Panjang:0,4 m

Lebar:1,2 m

Kedalaman air efektif:1,0 m

Tinggi Ruang bebas (Free board):0,2 m

\section{Ruang Bed Media :}

Panjang: $1,0 \mathrm{~m}$

Lebar:1,2 m

Kedalaman air efektif:1,0 m

Tinggi Ruang bebas (Free board):0,2 $\mathrm{m}$

Total Volume efektif:1,69 $\mathrm{m}^{3} \approx 1,7$ $\mathrm{m}^{3}$

Tebal dinding: $15 \mathrm{~cm}$

Chek

$\operatorname{td}($ jam $)=\frac{\text { Volume efektif }\left(m^{3}\right)}{\text { debit }\left(m^{3} / \text { hari }\right.}$

$\operatorname{td}=\frac{1,7 \mathrm{~m}^{3}}{20 \mathrm{~m}^{3} / \text { hari }} \times 24 \mathrm{jam} /$ hari

$$
=2,04 \mathrm{jam}
$$

jadi, waktu tinggal (td) di dalam bak $=2,04$ jam

> Waktu tinggal rata-rata :2,04 jam

$>$ Tinggi ruang lumpur:0,15 m

$>$ Tinggi bed media pembiakan mikroba

> Volume media pada biofilter anaerob
Beban BOD per volume media

$$
\begin{aligned}
& =\frac{1,44 \mathrm{Kg} \mathrm{BOD} / \text { hari }}{1,3 \mathrm{~m}^{3}} \\
& =1,1 \mathrm{Kg} \mathrm{BOD} / \mathrm{m}^{3} \text { hari }
\end{aligned}
$$

\section{F. Kebutuhan Oksigen}

Kebutuhan oksigen di dalam reaktor biofilter aerob sebanding dengan jumlah BOD yang dihilangkan.

Jadi, kebutuhan teoritis = jumlah BOD yang dihilangkan yaitu $1,44 \mathrm{Kg} / \mathrm{hari}$

Faktor keamanan di tetapkan $\pm 2,0$

Kebutuhan oksigen teoritis $=2 \times 1,44 \mathrm{Kg} / \mathrm{hari}$ $=2,88 \mathrm{Kg} /$ hari

Temperatur udara rata-rata $=28^{\circ} \mathrm{C}$

Berat udara pada suhu $28{ }^{\circ} \mathrm{C}=1,1725$ $\mathrm{Kg} / \mathrm{m}^{3}$

Diasumsikan jumlah oksigen di dalam udara $23,2 \%$

Sehingga,

Jumlah kebutuhan oksigen teoritis

$$
\begin{aligned}
&=\frac{2,88 \mathrm{Kg} / \text { hari }}{1,1725 \mathrm{Kg} / \mathrm{m}^{3} \times 0,232 \mathrm{~g} \mathrm{O}^{2} / \mathrm{g} \mathrm{Udara}} \\
&=10,58 \mathrm{~m}^{3} / \text { hari } \\
& \text { Efisiensi difuser }=5 \% \\
& \text { Kebutuhan Udara Aktual } \\
&=\frac{10,58 \mathrm{~m}^{3} / \text { hari }}{0,05} \\
&=211,6 \mathrm{~m}^{3} / \text { hari } \\
&=0,14 \mathrm{~m}^{3} / \text { menit } \\
&=146 \mathrm{Liter}_{\text {menit }}
\end{aligned}
$$

Jika kapasitas blower adalah 100 liter/menit dan terdiri dari 2 unit, maka transfer total udara $=200$ liter $/$ menit

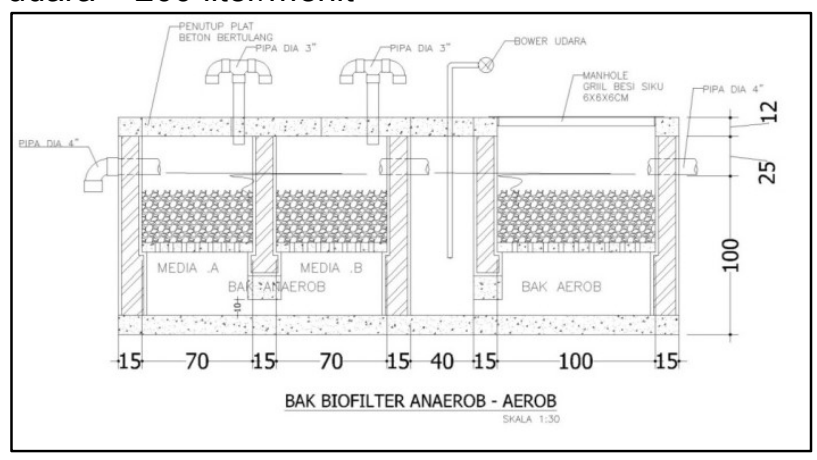

Gambar 3.5. Bak Biofilter Anaerob-Aerob
G. Bak Pengendapan
Sedimentasi Akhir
Debit Air Limbah:20 m³/hari

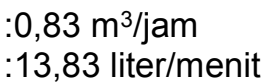
: $\quad B Q R_{1}$ masuk:26 mg/liter BOD keluar:20 mg/liter

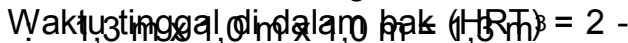
4 jam (JWWA dalam Said, 2006) 
Ditetapkan : waktu tinggal (td) limbah di dalam bak equalisasi $=2$ jam

Jadi,

Volume bak yang diperlukan

Dimensi Bak direncanakan

$$
\begin{aligned}
& =\frac{2}{24} \times 20 \mathrm{~m}^{3} \\
& =1,6 \mathrm{~m}^{3}
\end{aligned}
$$

Panjang:1,4 m

Lebar:1,2 m

Kedalanman air efektif:1,0 m

Ruang bebas (Free board):0,2 m

Volume efektif:1,6 $\mathrm{m}^{3}$

Tebal dinding: $15 \mathrm{~cm}$,

seperti pada gambar 3.6

\section{Chek}

$$
\begin{aligned}
& \operatorname{td}(\text { jam })=\frac{\text { Volume efektif }\left(\mathrm{m}^{3}\right)}{\text { debit }\left(\mathrm{m}^{3} / \text { hari }\right)} \\
& \operatorname{td}=\frac{1,6 \mathrm{~m}^{3}}{20 \mathrm{~m}^{3} / \text { hari }} \\
& =0,08 \text { hari } \mathrm{x} 24 \text { jam }=1,92 \text { jam } \\
& \approx 2 \text { jam } \\
& \text { jadi, waktu tinggal (td) di dalam bak } \\
& =2 \text { jam }
\end{aligned}
$$

Beban permukaan (surface loading)

$$
\begin{aligned}
& =\frac{20 \mathrm{~m}^{3} / \text { hari }}{1,6 \mathrm{~m} \mathrm{x} 1,0 \mathrm{~m}} \\
& =12,5 \mathrm{~m}^{3} / \mathrm{m}^{2} \cdot \text { hari }
\end{aligned}
$$

$>$ Waktu tinggal pada saat beban puncak = 1 jam (asumsi jumlah limbah $2 \mathrm{x}$ jumlah rata-rata)

> Beban permukaan (surface loading) rata-rata $=12,5$ $\mathrm{m}^{3} / \mathrm{m}^{2}$.hari

\begin{tabular}{|c|c|c|c|c|c|c|c|}
\hline \multirow[b]{2}{*}{ No } & \multirow[b]{2}{*}{ Nama Bak } & \multicolumn{6}{|c|}{ Dimensi Bak } \\
\hline & & $\begin{array}{c}\text { Vol. yg diperlukan } \\
\left(\mathrm{m}^{3}\right)\end{array}$ & $\begin{array}{c}P \\
(m)\end{array}$ & $\begin{array}{c}L \\
(m)\end{array}$ & $\begin{array}{c}T \\
(m)\end{array}$ & $\begin{array}{l}\text { Free Board } \\
(\mathrm{m})\end{array}$ & $\begin{array}{c}\text { Vol. Efektif } \\
\left(\mathrm{m}^{3}\right)\end{array}$ \\
\hline 1 & Bak Pre Treatment & 1,0 & 1,0 & 1,0 & 1,0 & 0,2 & 1,0 \\
\hline 2 & Bak Pemisah Lemak/Minyak & 1,0 & 1,0 & 1,0 & 1,0 & 0,2 & 1,0 \\
\hline 3 & Bak Equalisasi & 1,6 & 1,4 & 1,2 & 1,0 & 0,2 & 1,6 \\
\hline 4 & Bak Pengendapan Awal & 1,6 & 1,4 & 1,2 & 1,0 & 0,2 & 1,6 \\
\hline 5 & Bak Biofilter Anaerob & 1,6 & 1,4 & 1,2 & 1,5 & 0,2 & 1,6 \\
\hline \multirow[t]{3}{*}{6} & Bak Biofilter Aerob & & & & & & \\
\hline & a. Ruang Aerasi & 1,7 & 0,4 & 1,2 & 1,0 & 0,2 & 1,7 \\
\hline & b. Ruang Bed Media & & 1,0 & 1,2 & 1,0 & 0,2 & \\
\hline 7 & Bak Pengendapan Akhir & 1,6 & 1,4 & 1,2 & 1,0 & 0,2 & 1,6 \\
\hline \multicolumn{2}{|l|}{ Total } & & 10 & & & & \\
\hline
\end{tabular}

> Beban permukaan pada saat puncak $=25 \mathrm{~m}^{3} / \mathrm{m}^{2}$. hari

$>$ Beban permukaan $=20-50$ $\mathrm{m}^{3} / \mathrm{m}^{2}$.hari

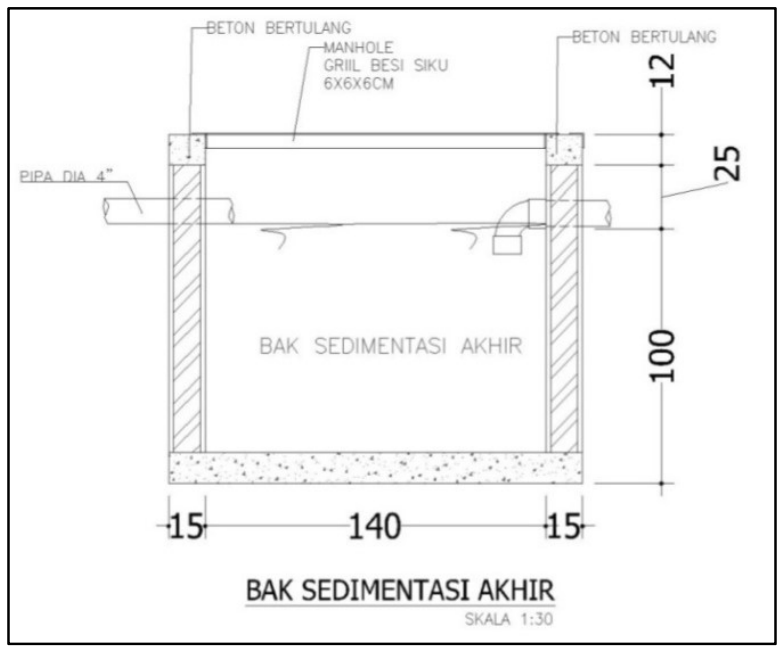

Gambar 3.6. Bak Sedimentasi Akhir

Berdasarkan perhitungan analisis perencanaan diperoleh rekap dimensi IPAL seperti pada tabel 3.1 berikut.

Tabel 3.1. Rekap dimensi IPAL Poliklinik UNIPA Surabaya

\section{KESIMPULAN}

Perencanaan pembangunan IPAL Poliklinik UNIPA Surabaya akan dibangun pada lahan seluas $12 \mathrm{~m}^{2}$ dengan panjang total IPAL yaitu $10 \mathrm{~m}$ dan lebar $1,2 \mathrm{~m}$.
Bangunan IPAL Poliklinik terdiri dari bak pre treatment, bak pemisah minyak/lemak, bak equalisasi, bak pengendapan awal, bak biofilter anaerob, bak biofilter aerob dan bak pengendapan akhir. 


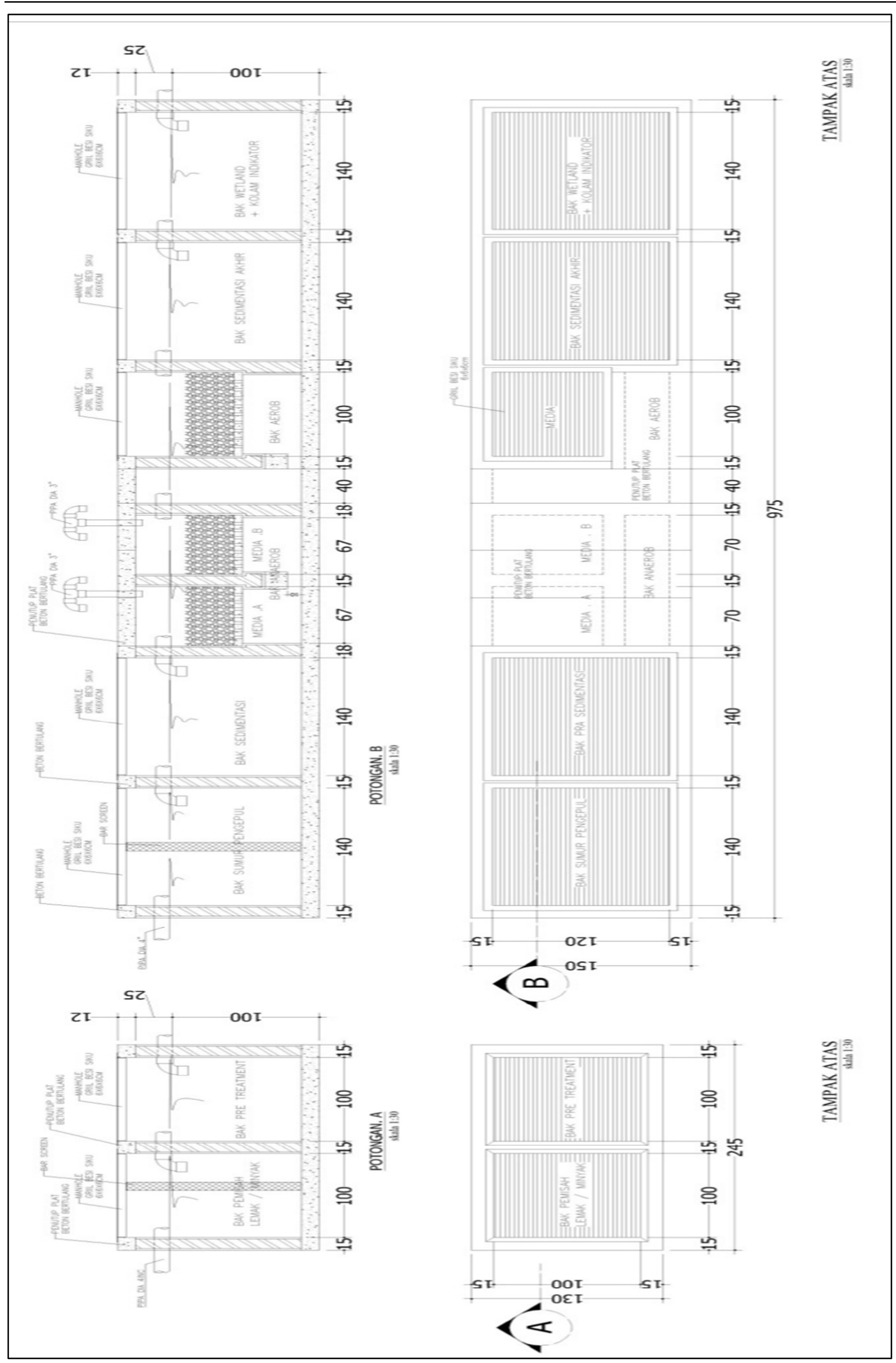

Gambar 3.7 Rancangan IPAL Poliklinik UNIPA Surabaya 


\section{DAFTAR PUSTAKA}

Ahmadi, Fahmi Umar, 1995. Konsep Penanggulangan Air Limbah Rumah Sakit. Jakarta.

BPPT, 2006, Teknologi Pengolahan Air Limbah Cair Sistem Biakan Melekat (Rumah Sakit, Domestik, Industri), Pusat Teknologi Lingkungan, Jakarta.

Keputusan Gubernur Daerah Tingkat I jawa Timur Nomor : 61 tahun 1999 tertanggal 19 juli 1999 tentang Baku Mutu Limbah Cair bagi Kegiatan Rumah Sakit di Propinsi daerah Tingkat I jawa Timur.

Metcalf \& Eddy, 2004, Wastewater Engineering Treatment and Reuse, Fourth Edition, McGrawHill Inc. New York.

Said, Nusa Idaman, 2006. Instalasi Pengolahan Air Limbah Rumah Sakit. Kelompok Tehnologi Pengolahan Air Bersih dan Air Limbah, Pusat Pengkajian dan Penerapan Lingkungan, BPPT, Jakarta.

Said, Nusa Idaman, 2006. Paket Tehnologi Pengolahan Air Limbah Rumah Sakit dengan Sistem Biofilter Anaerob-aerob, http://ejurnal.bppt.go.id , tanggal mengunduh 30 Januari 2012

Siregar, S. A, 2005. Instalasi Pengolahan Air Limbah. Kanisius, Jakarta.

Zaenal, A.Z, 2005. Analisis Bangunan: Menghitung Anggaran Biaya Bangunan. Gramedia PustakaUtama, Jakarta. 